\title{
O genoma humano pelas ruas de Avellaneda
}

\author{
The human genome on the streets of Avellaneda
}

\author{
Ricardo Ferraro \\ Professor da Universidad de Buenos Aires \\ Av. Leandro N. Alem 1067, piso 7 \\ Buenos Aires 1001 - Argentina \\ rferraro@inti.gov.ar \\ Adriana J. Bacciadonne \\ Diretora acadêmica do \\ International Doorway to Education \& \\ Athletics, Estados Unidos \\ Av. Libertador, 184 piso 6-A \\ Buenos Aires 1001 - Argentina \\ adrianajb@ciudad.com.ar \\ Alberto Díaz \\ Professor da \\ Universidad Nacional de Quilmes \\ Roque S. Peña 180 - (1876) \\ Bernal, Pcia. de Buenos Aires - Argentina \\ albdiaz@unq.edu.ar
}

$\mathrm{E}$ m dezembro de 1999, no âmbito da Vice-Presidência do Poder Executivo Nacional Argentino, criou-se a Secretaria de Modernização do Estado. Um de seus objetivos consistiu em aproximar, de um lado, o conhecimento científico e seus atores, e, de outro, a comunidade e seus problemas. Nesse cenário, nasceu o programa "Conhecimento e Sociedade", que colocou em prática os Diálogos Cidadãos.

Para introduzir os conceitos centrais que fundamentam os Diálogos Cidadãos, resumimos, a seguir, o relatório sobre o Projeto Genoma Humano feito pelos cidadãos que participaram do primeiro Diálogo Cidadão, em Avellaneda, província de Buenos Aires. Participaram desse Diálogo 13 mulheres e seis homens, com uma interessante diversidade sociocultural: quatro estudantes; duas enfermeiras; uma dona-de-casa, empregada e estudante; um aposentado; uma comerciante; dois docentes universitários; uma fonoaudióloga; um construtor; um funcionário; uma estudante e secretária; uma cabeleireira; um profissional formado em administração; uma assistente social e sindicalista, e uma integrante de Organização Não-Governamental (ONG) e de um 'centro escolar de prevenção'. 


\section{Apresentação do relatório sobre "A genética em debate"}

... Este Diálogo Cidadão, o primeiro a ser realizado em Avellaneda, na Argentina e na América Latina, colocou em marcha uma prática que pode ser de utilidade para a sociedade argentina.

Durante os quatro sábados de agosto, todos nós viemos interessados em satisfazer nossa necessidade de conhecimentos, vencendo temores, fazendo grandes esforços para ouvir e falar o mesmo idioma; constatamos o valor da participação, do trabalho em equipe e do compromisso. Com tudo isso, estamos orgulhosos pela responsabilidade que assumimos, ao aceitar o desafio, e também pelo resultado obtido.

Compreendemos que a ciência transforma em ritmo acelerado o mundo atual, que seus resultados contribuem para melhorar a vida cotidiana e que, em muitas ocasiões, gera dúvidas e temores com suas descobertas; que, em muitas ocasiões, tanto os que fazem ciência quanto nós cidadãos devemos dispor de um espaço público que nos una e nos permita apresentar dúvidas, expor nossas idéias e avançarmos juntos na busca de uma melhor qualidade de vida, individual e comunitária.

... Nos primeiros dois sábados, participaram quatro cientistas de primeira linha, relatando quais as perguntas mais comuns na área da biologia e quais os resultados já alcançados, trocando conosco informações e opiniões sobre as conseqüências presentes e futuras dessas descobertas. No terceiro e no quarto sábado, discutiu-se amplamente, em grupos e em plenária, para elaborar o Relatório que apresentamos hoje.

Compreendemos que o conhecimento do mapa genético humano abre portas para possibilidades imprevisíveis, ao mesmo tempo em que implica importantes questões éticas, trabalhistas e educativas e nos alerta para a necessidade de acompanhar de perto a orientação dos negócios vinculados a essas pesquisas e as manipulações de seus resultados.

\section{O relatório}

\section{A ciência e o povo: $O$ direito de conhecer e de decidir}

... queremos saber mais sobre os efeitos da biologia molecular e das biotecnologias na sociedade, saber mais sobre genética ... e se a genética servirá para melhorar ou para piorar a humanidade.

... por fim, vemos os cientistas ao nosso lado, nem longe, nem contrários a nós... a universidade e a ciência, abertas ao povo e com o povo.

Preocupam-nos as relações entre o poder econômico e o político, a propriedade e a concentração do conhecimento, e como um cidadão pode decidir sobre sua vida e influir na comunidade sem informação e sem se fazer escutar.

... a Unesco ... se declara "patrimônio da humanidade", mas quanta informação é - e será - pública e quanta será privada? Todos os cidadãos têm acesso à informação? $\mathrm{O}$ que acontecerá com as diferenças entre os ricos e os pobres?

... os programas educativos deveriam incorporar uma matéria que fale sobre a genética e a saúde, que inclua oficinas preventivas e visitas a laboratórios e centros de saúde; a 
formação de todos os médicos, por sua vez, deveria incluir os mais modernos progressos nessa disciplina, considerando o ser humano em sua totalidade e não apenas como um mero objeto de estudo.

\section{O social e o ético: Combater as discriminações}

Compreendemos a necessidade de se incorporarem concepções éticas e humanitárias quando se dispõe de novas ferramentas para evitar o sofrimento.

... nos perguntamos que fatores podem tornar a genética útil para melhorar ou para piorar o ser humano, e o que acontecerá com os sentimentos de todos nós, com nossos medos a respeito do futuro. Quem controla a informação? Como ela é gerenciada? Que tipo de informação chega a nós? É verdadeira?

Recomendamos que o conhecimento se democratize de forma sistemática, mas não apenas por meio desses encontros; que se incorporem esses temas ao currículo educativo, começando na escola primária, levando em conta os riscos de discriminação e exclusão e a importância dos valores e as questões éticas como parte de um saber que nos transforme em cidadãos responsáveis.

\section{O político e o social: As responsabilidades do Estado}

... preocupa-nos nosso atraso biotecnológico; que o Estado cumpra com seu indelegável papel de fiador e construtor do bem comum; que proteja a pesquisa científica como um instrumento essencial para a humanidade. Mas as obrigações do Estado não excluem as dos cidadãos, cujo compromisso é fundamental.

\section{O político e o econômico: patrimônio da humanidade ou dos grupos econômicos e do poder político?}

Nós, cidadãos de Avellaneda, tomamos consciência da necessidade de informar a comunidade e de alertá-la para evitar a manipulação da informação. É preciso evitar, também, que mais uma vez as decisões mais importantes caiam nas mãos dos grupos econômicos mais poderosos ...

Recomendamos que se disponibilizem à comunidade espaços ou formas de comunicação, para que o cidadão receba a informação e possa debater e propor seus pontos de vista acerca dos avanços científicos e dos riscos de sua manipulação, por razões políticas ou por interesses econômicos. É preciso haver cidadãos alertas, mais bem informados; assim, em temas com essas características se construirão verdadeiras políticas de Estado.

\section{A genética e as religiões}

Nós, cidadãos em Avellaneda, tomamos consciência das múltiplas relações entre a genética moderna e as religiões, da importância do religioso e do papel das instituições religiosas, sem esquecermos que os problemas éticos não se restringem às crenças religiosas e que dizem respeito tanto aos religiosos quanto aos não-religiosos. 
... recomendamos que os grupos religiosos participem das discussões relacionadas às formas de sustentar eticamente os avanços científicos, e, em última instância, que opinem e aconselhem, mas que não decidam.

\section{O futuro social}

... recomendamos, também, que se estabeleçam novos e sólidos vínculos entre cidadãos, cientistas e o Estado, para levar adiante tarefas de conscientização pública e de educação. As instituições da comunidade, sem fins lucrativos, podem cumprir um papel muito importante para levar adiante uma atualização permanente da informação e de sua possível aplicação.

Recomendamos a criação de redes de cidadãos em resposta à necessidade de informação e de conhecimento acerca das concepções éticas e humanitárias, para sustentar eticamente os avanços científicos e para tomar parte na multiplicação da informação e do debate em todo o país e não apenas nas grandes cidades.

\section{Conclusões do relatório}

Acreditamos que o resultado deste Diálogo demonstra a necessidade de se continuar com essa modalidade de consulta pública para tratar temas científicos de interesse social.

Resgatamos a importância de nossa participação nesse tipo de atividades que nos permitem trocar experiências e compartilhar problemáticas similares em diferentes âmbitos.

Apreciamos a importância de se construírem consensos entre pontos de vista distintos como forma de otimizar o trabalho.

Sustentamos que se deve pensar em como multiplicar amplamente essa experiência pelo país, para que não se limite apenas a algumas grandes cidades.

Nós, que participamos dessa iniciativa, comprometemos-nos a colaborar em debates futuros, a ter muito boa vontade e a deixarmos de ser espectadores para nos tornarmos participantes ativos em diferentes temas da sociedade.

Devemos encontrar a forma de gerar a motivação necessária na cidadania para alcançar o compromisso de todos.

Acreditamos, finalmente, que a continuidade de esforços como o que estamos realizando irá permitir que os seres humanos encontrem na ciência contribuições para uma vida mais digna.

\section{Considerações gerais e opiniões da coordenação}

Com uma metodologia semelhante, realizou-se entre agosto e outubro de 2000, em Pergamino, outro Diálogo Cidadão, sobre sementes e alimentos geneticamente modificados ou 'transgênicos'. Paralelamente, iniciou-se a organização de um terceiro, sobre "informática e democracia", em Mar Del Plata, com apoio da Prefeitura e do Conselho Deliberativo do General Pueyrredón e da Universidade Nacional de Mar Del Plata. 
O nome Diálogo Cidadão vem de um dos pilares da reforma do Estado realizada pela Vice-Presidência da Nação, que consistiu em "aproximar o Estado da sociedade, do povo", do que o cidadão médio quer e necessita, e em ampliar os mecanismos de escuta e participação social.

Em 7 de outubro de 2000, a renúncia de Carlos Alvarez nos deixou sem Vice-Presidência, sem modernização do Estado, sem "Conhecimento e Sociedade", sem Diálogos Cidadãos e sem a possibilidade de estabelecer um novo contrato entre ciência e sociedade.

As questões-chave dos Diálogos Cidadãos estão diretamente relacionadas aos nossos objetivos iniciais. Por exemplo, decidir os critérios para escolha do lugar de realização; promover a 'venda' do projeto e incluir os sócios locais, cuja colaboração tenha sido fundamental para a concretização dessas atividades; encontrar no tema a ser apresentado o equilíbrio exato entre uma generalização - que poderia pecar pela superficialidade - e uma especificidade inacessível à maioria; conseguir que os cientistas e especialistas façam apresentações didáticas, em uma linguagem simples que respeite a diversidade e a heterogeneidade dos cidadãos.

A convocatória para participação nos Diálogos Cidadãos exige transparência e uma divulgação muito cuidadosa, para evitar suspeitas; no mesmo sentido, a seleção dos participantes deve constituir uma amostra representativa da comunidade local. É essencial que a estrutura da atividade, os recursos didáticos e pedagógicos e as dinâmicas de grupo consigam motivar as pessoas, motivá-las a uma participação sem lideranças pontuais, retê-las durante quatro sábados e fazê-las se comprometer tanto com o processo de intercâmbio de idéias como com a elaboração do relatório final.

Merece referência à parte o silêncio da mídia nacional, do jornalismo especializado e do meio universitário, tal como foi assinalado por um dos participantes. Apatia, desinteresse, interesses criados? Não sabemos, mas trata-se, sem dúvida, de um dos grandes desafios a serem superados se o objetivo é a multiplicação dos Diálogos Cidadãos em outras localidades. O papel dos meios de comunicação de massa é imprescindível: como difusores, como críticos, como promotores, como cronistas e como comunicadores que se fazem necessários em uma atividade com as características desses encontros; como um ator-chave, finalmente, para estabelecer "um novo contrato social" entre a ciência e a sociedade e propor elementos que possam ajudar nesses desafios em iniciativas futuras.

"Não é o conhecimento que é perigoso, mas sim a ignorância", escreve François Jacob em La souris, la mouche et l'homme. Acrescentamos que o perigo está na ignorância da sociedade civil e em seu poder para impedir a maturação de democracias precárias como a nossa.

Com base nessas iniciativas bem sucedidas, concluímos que os Diálogos Cidadãos são muito baratos. Em termos de valores, relativos a 2000, o custo de cada Diálogo Cidadão excluindo o tempo dedicado pelos organizadores - não alcançou o salário mensal de um gerente de uma empresa de nível médio. Tudo indica, portanto, que se requer apenas vontade política para fazê-lo. Quais são os ingredientes? Recursos humanos (organizadorescoordenadores, facilitadores e cientistas-apresentadores), local para as reuniões - e um computador -, e alguns recursos financeiros para a divulgação no âmbito local (pouca coisa: cartazes em escolas, locais públicos e supermercados e notas na mídia local, como o canal a cabo e algum jornal), além da publicação dos relatórios finais.

Tradução do espanhol para o português: Carla Almeida. 


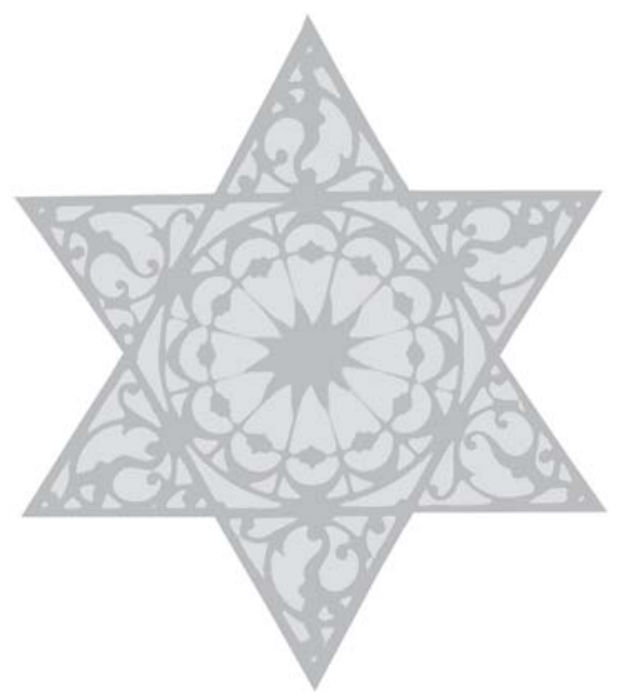

